\title{
Haemodialysis in Severe Barbiturate Poisoning
}

\author{
H. A. LEE,* M.B., B.S., B.SC., M.R.C.P. ; A. C. AMES, $†$ M.B., B.S., B.SC.
}

Brit. med. F., 1965, 1, 1217-1219

The treatment of cases of barbiturate poisoning has been improved in recent years by the introduction of more efficient techniques for the removal of the circulating drug. These include forced diuresis (Ohlsson, 1949 ; Ohlsson and Fristedt, 1962) and forced diuresis and alkalinization (Mollaret, Rapin, Pocidalo, and Monsallier, 1959 ; Lassen, 1960 ; Myschetzky and Lassen, 1963). The infusions used include urea, solutions of electrolytes, and, more recently, mannitol (Cirksena, Bastian, and Barry, 1962). The mortality rate and incidence of complications have been reduced by these regimes, the prompt application of which should also reduce the need for haemodialysis.

Haemodialysis is the most efficient and rapid way of eliminating barbiturates (Alwall, Lindgren, and Lunderquist, 1952 ; Berman, Jeghers, Schreiner, and Pallotta, 1956 ; Linton, Luke, Speirs, and Kennedy, 1964). This paper reports our experience of 15 patients with severe barbiturate poisoning, all of whom required assistance from a respirator, and seven of them had a cardiac arrest. Some of the problems arising in the management of such patients are discussed and an attempt has been made to define the criteria for haemodialysis.

\section{Methods and Material}

Over a period of 18 months 181 patients with barbiturate poisoning were admitted to this hospital, of whom one died. The frequency and type of barbiturate taken were as follows: amylobarbitone 63 , butobarbitone 35 , phenobarbitone 27 , quinalbarbitone 18 , pentobarbitone 16 , amylobarbitone with quinalbarbitone 7, unidentified 15 .

Barbiturate Analysis.-Plasma from all patients with suspected barbiturate poisoning was screened for the presence of barbiturate, using the method described by Wallenius, Zaar, and Lausing (1963). In unconscious patients a plasma barbiturate level was estimated by the method of Broughton (1956). Partial identification of barbiturate was made either from the effect of alkaline hydrolysis on the spectral absorption (Broughton, 1956) or by paper chromatography (Podmore, 1962).

Forced Diuresis and Alkalinization.-Gastric aspiration or lavage was used only on those who were fully conscious or only slightly drowsy. All patients who were drowsy or unconscious on admission were immediately treated by forced diuresis and alkalinization provided their systolic blood-pressure was above $70 \mathrm{~mm} . \mathrm{Hg}$ and there was no clinical evidence of cardiac disease. Plasma electrolytes and the urine specific gravity were estimated at the outset. The technique for forced diuresis and alkalinization was as follows: a "Y-giving set" was used for intravenous infusion and closed urinary drainage was established; $500 \mathrm{ml}$. of $10 \%$ mannitol was infused over four hours through one channel, while through the other $500 \mathrm{ml}$. of $5 \%$ dextrose, $500 \mathrm{ml}$. of $3 \% \mathrm{NaHCO}_{3}$, and $500 \mathrm{ml}$. of $0.9 \%$ saline were infused in rotation. During the first two hours 3 litres of fluid was given through this second channel, and then the infusion rate was adjusted to maintain a urine flow of at least

* Lecturer in Medicine, King's College Hospital, London.

† Registrar in Chemical Pathology, King's College Hospital, London.
400-500 ml. an hour. The urine $p \mathrm{H}$ was kept at approximately 7.6 (Lassen, 1960) by adjusting the amount of sodium bicarbonate given. This was done by occasionally omitting it from the rotation of solutions going through the second channel as stated. During every six hours at least $2 \mathrm{~g}$. of potassium chloride was given intravenously, and often very much more was required. The serum potassium was estimated at least eight-hourly. Hourly fluid balances were measured and all relevant clinical observations noted on a special chart (Cam, Grogono, and Lee, 1964), and plasma barbiturate levels were estimated periodically. This regime was continued until full consciousness was regained.

Criteria for Haemodialysis.-Patients were dialysed on admission if the barbiturate level was greater than $3-5 \mathrm{mg}$./ $100 \mathrm{ml}$. in the case of short-acting and intermediate-acting compounds-for example, quinalbarbitone and amylobarbitone -or above $10 \mathrm{mg} . / 100 \mathrm{ml}$. of long-acting compounds-for example, phenobarbitone. Occasionally patients will need dialysis with a plasma level of a short-acting barbiturate below $3 \mathrm{mg} . / 100 \mathrm{ml}$., particularly in the elderly and the very young or where phenothiazines have been taken concurrently. Patients were haemodialysed during treatment with forced diuresis and alkalinization if (1) the blood-pressure continued to fall, thus contraindicating further use of the treatment ; $(2)$ the level of unconsciousness deepened-for example, response to painful stimuli ; (3) the reflexes became unobtainable; or (4) the plasma barbiturate level continued to rise.

Dialysis Technique.-For haemodialysis a Kolff twin-coil artificial kidney (Kolff, Watschinger, and Vertes, 1956) was used. Forced diuresis and alkalinization were continued during the haemodialysis and plasma barbiturate levels were measured hourly. Haemodialysis was continued until the patient regained consciousness or became restless, or until the plasma barbiturate level remained constant for a period of three to four hours with insignificant amounts of barbiturate being removed in the dialysing fluid. Those patients who failed to regain consciousness and who had a constant plasma barbiturate level were closely observed, and at the first signs of clinical deterioration a second haemodialysis was done. The arterial and venous cannulae were therefore kept patent until consciousness was regained.

\section{Results}

The Table summarizes the clinical and biochemical findings in the 15 patients with severe barbiturate poisoning who required urgent haemodialysis. Those cases in which a long interval elapsed between ingestion of the drug and subsequent haemodialysis had been referred from other hospitals. External cardiac massage combined with intravenous $8.4 \%$ sodium bicarbonate was used for those who had a cardiac arrest (Stewart, 1964). Cases 2, 10,12, and 15 required a second haemodialysis because either their clinical state deteriorated or their plasma barbiturate level rose.

Various depths of hypothermia, recorded rectally, were coserved, ranging from 83 to $96^{\circ} \mathrm{F}$. $\left(28.3\right.$ to $\left.35.6^{\circ} \mathrm{C}\right)$. A shortacting barbiturate was in every case responsible for the more severe degrees of hypothermia. In those patients with temperatures below $88^{\circ} \mathrm{F} .\left(31.1^{\circ}\right.$ C.) the electrocardiogram showed 
typical J waves (Emslie-Smith, 1958) and a variety of ST segment changes. Bradycardia was often seen, but no other altered cardiac rhythms were observed. There was no correlation between the depth of hypothermia and the occurrence of cardiac arrest. Artificial ventilation and the forced alkaline diuresis used in these patients counteracted the anoxia and respiratory acidosis (McNicol and Smith, 1964) and metabolic acidosis (Brewin, Gould, Nashat, and Neil, 1955) often found in hypothermia. All patients with hypothermia were treated by rapid total body rewarming in specially heated cubicles and with intravenous hydrocortisone (Duguid, Simpson, and Stowers, 1961). The body temperature of those patients dialysed while still hypothermic could be raised on an average by $1^{\circ} \mathrm{F}$. $\left(0.55^{\circ}\right.$ C. $)$ per hour of dialysis, using a dialysing fluid temperature of $37^{\circ} \mathrm{C}$.

The time taken to regain consciousness after dialysis is related to the type of barbiturate taken. Patients treated for phenobarbitone or barbitone poisoning regained consciousness during dialysis and remained conscious after their final dialysis. Consciousness was regained towards the end of dialysis or within 10 hours after dialysis in those patients poisoned with butobarbitone. A much longer interval occurred in patients with amylobarbitone or other short-acting barbiturate intoxication. Here none regained consciousness during dialysis, and only did so some 20 to 60 hours after the final dialysis.

The hourly estimations of plasma barbiturate levels during haemodialysis show that all types of barbiturate, particularly
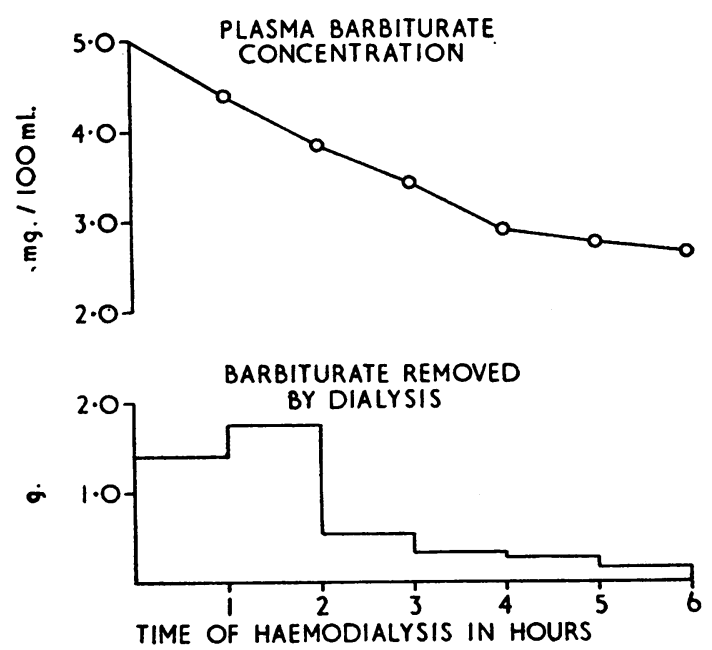

Rate of reduction of plasma barbiturate during haemodialysis and amounts recovered from dialysate in a patient with butobarbitone poisoning. the short-acting compounds, were rapidly removed during the first three hours. The plasma levels then fell more slowly and tended to level off, although the barbiturate concentration in the dialysate during this period showed that significant amounts of the drug were being removed. Eventually a stage was reached when only small amounts were being removed, and further haemodialysis appeared to be of little value (see Chart). In all cases the final plasma barbiturate level was reduced to a value below the generally accepted lower limit of the lethal range for long-acting compounds-that is, $10 \mathrm{mg} . / 100 \mathrm{ml}$. and short-acting compounds-3 mg. $/ 100 \mathrm{ml}$. (Berman et al., 1956).

\section{Discussion}

The main object of treatment is the removal of barbiturate from the patient. There is general agreement that gastric lavage is worth while only if done within three hours of ingestion (Harstad, Møller, and Simesen, 1942 ; Allan, 1961 ; Mallinson, 1964), and preferably in conscious patients. The intubation necessary to permit gastric lavage in the unconscious patient may induce a cardiac arrest or vomiting, and such complications far outweigh the advantages. Allan (1961) suggested that failure to give a gastric lavage would not constitute medico-legal negligence, and this has been accepted in Scandinavia (Clemmesen and Nilsson, 1961).

The majority of patients respond to forced diuresis and alkalinization, which was introduced to increase the rate of excretion of barbiturates via the patients' kidneys. Haemodialysis is necessary for the most severely poisoned patients, where forced diuresis would remove the drug too slowly for survival. Of 169 patients admitted direct to this hospital, only two required haemodialysis. The other 13 patients in this series were specially referred from other hospitals.

All patients with barbiturate poisoning who were drowsy or unconscious on reception in the casualty department were immediately started on a forced diuresis and alkalinization regime without waiting for the results of plasma electrolyte and urea levels or other urinary investigations as suggested by Linton et al. (1964) and Mallinson (1964). We have not had any complications with this regime, but a careful watch was kept on the fluid balance. We consider that if this regime was more widely adopted fewer patients would become unconscious or require haemodialysis.

Analeptics seem to have no place in the treatment of barbiturate poisoning (Balagot, Tsuji, and Sadove, 1961; Clemmessen, 1963), and Megimide (bemegride) is especially undesirable as it interferes with the estimation of plasma

Clinical and Biochemical Details of 15 Surviving Patients with Severe Barbiturate Poisoning Requiring Haemodialysis

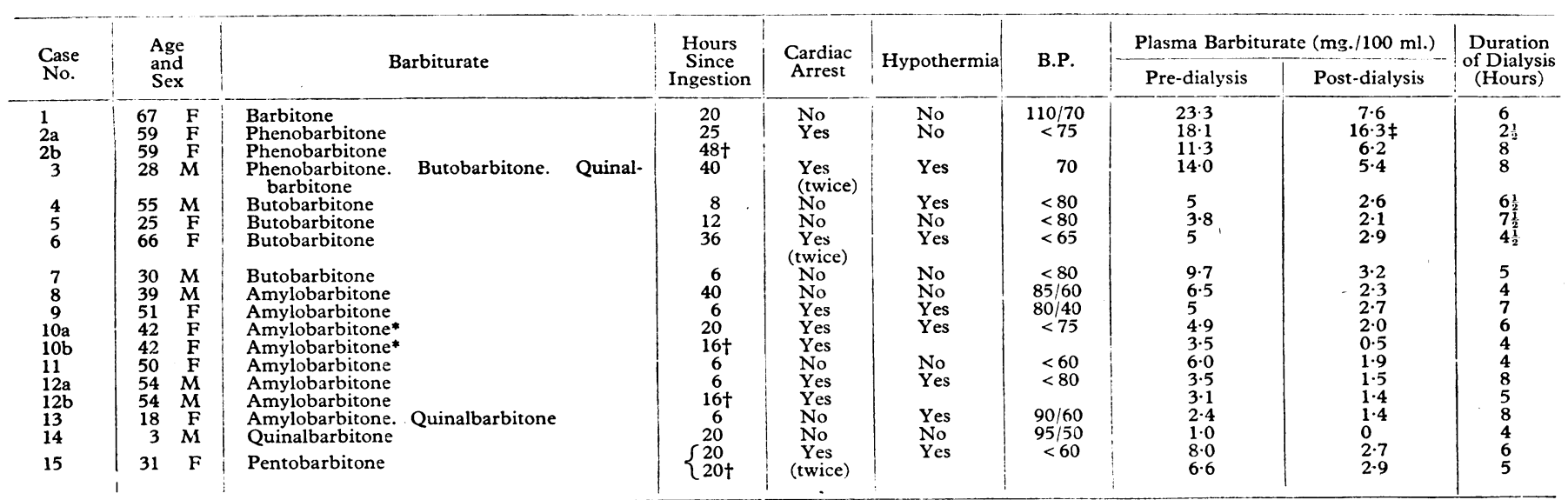

* Phenothiazine also taken. + Hours after first dialysis. ‡ Patient became conscious and so restless that dialysis had to be stopped.

All patients required assisted respiration. 
barbiturates. Phenothiazine drugs may also interfere in a similar way.

A rapid and efficient method of eliminating barbiturate by dialysis is vital, especially for short-acting compounds, which can kill rapidly even when the concentration in the plasma is low. The commonly used methods of dialysis are those employing large artificial kidneys-for example, Kolff twin-coil-small artificial kidneys-for example, Minicoil-and peritoneal dialysis. The efficiency of the Kolff twin-coil compared with that of Minicoil and peritoneal dialysis in respect of phosphate and urea clearances has been shown to be $4: 1$ (Lee, Anderson, and Brooks, 1964). Berman and Vogelsang (1964) found a similar relation for barbiturate clearance when comparing the Kolff twin-coil with peritoneal dialysis. Ideally, therefore, only large artificial kidneys should be used for severely ill patients. Using the Kolff twin-coil kidney, we have always been able to begin treatment within one hour of admission. Peritoneal or Minicoil dialysis in our patients with cardiac arrest would probably have taken too long and been too inefficient for survival.

All patients severely poisoned with long-acting or shortacting barbiturates benefit from haemodialysis. We do not agree with Linton et al. (1964) that those patients poisoned with long-acting compounds benefit more than others. From experience gained in our series, small amounts of short-acting compounds removed by haemodialysis may be more critical in saving life than the larger amounts of long-acting compounds removed. This is probably related to the better tolerance shown to the latter group.

In one patient (Case 12) during dialysis the plasma barbiturate level rose from 3.5 to $4.2 \mathrm{mg}$. $/ 100 \mathrm{ml}$. over the first two hours. This may be related " to reactivation of a narcotized intestinal tract" during dialysis (Schreiner, 1958).

Cases 10, 12, and 15 in our series showed a rebound phenomenon after the first haemodialysis, in which their clinical condition deteriorated and the plasma barbiturate rose again. This secondary rise might have been due either to a resumption of gastro-intestinal reabsorption of the drug or to continued release of free barbiturate from lipoid- or protein-binding sites or other body pools. The phenomenon is not seen in those patients who are dialysed 48 hours or more after ingestion (Jørgensen and Wieth, 1963).

The levelling off of plasma barbiturate values towards the end of haemodialysis, together with decreasing elimination in the bath fluid, may be partly due to the falling gradient between plasma and dialysate and to some extent to protein-binding (Honey and Jackson, 1959). Recent in vitro studies (Wieth, Funder, and Brun, 1964) have shown that protein binding of allyl isopropyl barbituric acid reduced elimination by a maximum of $25 \%$.

Only one other similar series of patients with severe barbiturate poisoning has been treated with forced diuresis and haemodialysis (Linton et al., 1964), and there one of 23 patients died. Survival of all our patients is remarkable when it is remembered that almost half of them had a cardiac arrest. The most valuable indications for treatment, however, still remain clinical.

\section{Summary}

A series of 15 patients surviving very severe barbiturate poisoning is described. Severe hypothermia developed in eight patients, all of whom had taken short-acting barbiturates. Seven patients had at least one cardiac arrest. A marked rebound phenomenon was observed in four patients who required a second haemodialysis. All patients were treated with forced diuresis and alkalinization in addition to haemodialysis. A method of forced diuresis and alkalinization is described and the importance of early implementation of such a diuresis regime is stressed. An attempt to define strict criteria for haemodialysis is made.

We would like to thank Dr. Clifford Hoyle, Director of the Department of Medicine, and Professor C. H. Gray, of the Department of Chemical Pathology, for their encouragement and helpful criticisms in the preparation of this paper.

\section{REFERENCES}

Allan, B. C. (1961). Med. F. Aust., 2, 513.

Alwall, N., Lindgren, P., and Lunderquist, A. (1952). Acra med. scand.,

143, 299. . Tsu,i, H., and Sadove, M. S. (1961). F. Amer. med. Ass., 178,1000 .

Berman, L. B., Jeghers, H. J., Schreiner, G. E., and Pallotta, A. J. (1956). Ibid., 161, 820.

_ and Vogelsang, P. (1964). New Engl. F. Med., 270, 77.

Brewin, E. G., Gould, R. P., Nashat, F. S., and Neil, E. (1955). Guy's Hosp. Rep., 104, 177.

Broughton, P. M. G. (1956): Biochem. F., 63, 207.

Cam, J. F., Grogono, A. W., and Lee, H. A. (1964). Lancet, 2, 1168.

Cirksena, W. J., Bastian, R. C., and Barry, K. G. (1962). Symposium on Clinical and Experimental Use of Mannitol, p. 31. Walter Reed Army Institute of Research, Washington, D.C.

Clemmesen, C. (1963). Dan. med. Bull., 10, 97.

- and Nilsson, E. (1961). Clin. Pharmacol. Ther., 2, 220

Duguid, H., Simpson, R. G., and Stowers, J. M. (1961). Lancet, 2, 1213. Emslie-Smith, D. (1958). lbid., 2, 492.

Harstad, E., Møller, K. O., and Simesen, M. H. (1942). Acta med. scand., $112,1134$.

Honey, G. E., and Jackson, R. C. (1959). Brit. med. F., 2, 1134

Jørgensen, H. E., and Wieth, J. O. (1963). Lancet, 1, 81.

Kolff, W. J., Watschinger, B., and Vertes, V. (1956). f. Amer. med. Ass., 161, 1433.

Lassen, N. A. (1960). Lancet, 2, 338.

Lee, H. A., Anderson, J., and Brookes, P. L. (1964). Proceedings of European Dialysis and Transplant Association. In press.

Linton, A. L., Luke, R. G., Speirs, Isobel, and Kennedy, A. C. (1964). Lancet, i, 1008 .

McNicol, M. W., and Smith, R. (1964). Brit. med. 7., 1, 19.

Mallinson, C. (1964). Guy's Hosp. Gaz., 78, 478.

Mollaret, P., Rapin, M., Pocidalo, J. J., and Monsallier, J. F. (1959). Presse méd., 67, 1435.

Myschetzky, A., and Lassen, N. A. (1963). f. Amer. med. Ass., 185, 936.

Ohlsson, W. T. L (1949). Nord. Med., 42, 1471, 1904.

and Fristedt, B. I. (1962). Lancet, 2, 12.

Podmoiner, G. E. (1958). Arch. intern. Med., 102, 896.

Schreiner, G. E. (1958). Arch. intern. Med., 10

Stewart, J. S. S. (1964). Brit. med. F., 1, 476.

llenius, G., Zarr, B., and Lausing, E. (1963). Scand. f. clin. Lab.

Invest., 15, Suppl. No. 69, p. 252.
Wieth, J. O., Funder, J., and Brun, C. (1964). F. Lab. clin. Med., 64, 60. 